\title{
Skin Care Management For Medical And Aesthetic Procedures To Prevent Scarring
}

This article was published in the following Dove Press journal:

Clinical, Cosmetic and Investigational Dermatology

\author{
Marie Jourdan' \\ Diane C Madfes (1D) ${ }^{2}$ \\ Emerson Lima ${ }^{3}$ \\ Yan $\operatorname{Tian}^{4}$ \\ Sophie Seité $\mathbb{D D}^{5}$ \\ 'Centre Laser International de la Peau - Paris \\ (CLIPP), Paris, France; ${ }^{2}$ Mount Sinai School \\ of Medicine, New York, NY, USA; ${ }^{3}$ Santa \\ Casa de Misericórdia, Jaqueira, Recife, Brazil; \\ ${ }^{4}$ Department of Dermatology, The General \\ Hospital of Air Force, Beijing, People's \\ Republic of China; ${ }^{5}$ La Roche-Posay \\ Dermatological Laboratories, \\ Levallois-Perret, France
}

Correspondence: Sophie Seité

La Roche-Posay Dermatological

Laboratories, 62 quai Charles Pasqua,

Levallois-Perret 92300 , France

$\mathrm{Tel}+33$ I 49643340

Email sophie.seite@loreal.com

\begin{abstract}
An estimated 100 million people per year in developed countries acquire scars following surgical procedures whether it be elective, therapeutic or reparative. Scarring from surgery can have a significant physical and psychological impact depending on the colour, relief, size, body location, surface area or function. Whether a procedure be life-saving such as a mastectomy, a caesarean, or a mole excision, or aesthetic such as breast reconstruction or laser treatment, patients are increasingly concerned with having an aesthetic scar outcome. With improved surgical and technological advances, elective surgery and cosmetic procedures are becoming safer and easier to perform in both hospitals and outpatient clinics. This means that more people elect to undergo procedures for an increasing number of indications on varied body areas including the face, back and limbs but also breasts, ears or genitalia. Therefore, taking the final scar outcome into consideration both before and after a procedure is becoming particularly important to ensure that controlled healing occurs with minimal discomfort. As the healing process varies from one procedure to another, and from one body part to another, each wound requires specific care. Dermatologists are well placed to manage wound healing but there remains a need for them to be involved in wound management and help surgeons better manage the wound healing process beyond wound closure and infection control. Basic skin care can play a role to protect the skin barrier function, control inflammation and enhance natural healing. The objective of this review is to provide recommendations based on published literature for the role basic skin care plays in supporting continued wound management following invasive procedures.
\end{abstract}

Keywords: procedure, scar, surgery, wound-healing, skin care, wound management

\section{Introduction}

An estimated three to four people per 1000 population live with one or more wounds. ${ }^{1}$ 100 million people living in developed countries acquire scars following invasive procedures, elective or trauma surgery ${ }^{2-4}$ and these patients increasingly value the aesthetic quality of the scar as being part of a successful outcome. ${ }^{2}$

Scars form from any traumatic event that breaks the cutaneous integrity. Commonly, this occurs following routine surgical procedures, trauma wounds, burns or dermatologic excisions. Increasingly, cosmetic surgery, cosmetic procedures (laser, dermabrasion, fillers, microinjections, peelings and micro-needling) are also potential source of scars. Although most surgical procedures or traumatic injuries produce a wound, some cosmetic procedures create a skin injury that stimulates the body's natural healing process for the desired effect. (eg $\mathrm{CO}_{2}$ resurfacing). Furthermore, various pathologies such as infections or dermatitis can lead to scarring i.e. scleroderma, surgical management of Dupuytren's contracture.

The psychosocial effects of scarring is well documented. ${ }^{5,6}$ Patients report having reduced self-esteem, being stigmatised, and having disrupted daily activities, anxiety and 
depression. ${ }^{7,8}$ The physical effects of scarring include dryness, itchiness, stiffness, tenderness and pain. Thus, managing the healing process is particularly important to ensure wounds are managed appropriately to heal rapidly, with minimal pain and with a cosmetically acceptable appearance.

Surgical techniques, postoperative care and management of patient-specific circumstances have significantly reduced healing time, wound tension and scar formation. ${ }^{9,10}$ However, once the wound is clean and closed, approximately 2-3 weeks post-intervention, many surgeons discontinue scar management, leaving "Mother Nature" to take its course. Yet, remodelling and scar formation continues for several months, up to a year after wound closure and may be compromised by patient specific factors. ${ }^{11}$ This lack of continued scar management and skincare support following skin injury varies between institutions and practitioners, possibly due to a lack of evidence concerning non-medical scar management techniques. For example, a recent survey of burn therapists reported that responders recommended applying moisturisers but were unable to cite a reference or evidence to support their choice. ${ }^{12}$

Although dermatologists are well placed to manage wound healing, there is need for them to be further involved with clinicians, surgeons and patients throughout the wound healing process and to be able to advise on the role basic skin care that can play to enhance natural healing. ${ }^{12}$ To our knowledge, there are no systematic reviews or evidence-based studies to support using basic skin care in scar prevention and management, despite the anecdotal recordings of their use.

The objective of this review is to summarise the evidence for basic skin care and provide practical recommendations to minimise scarring following surgical and cosmetic procedures.

\section{Search Strategy}

The search strategy aimed to identify all published literature concerning wound formation, pathophysiology and the use of basic skin care in managing scars from a wide variety of surgical and cosmetic procedures. Reference lists of all papers selected for full text retrieval were then hand searched for potential additional citations.

\section{Common Injury Types, Wounds And Symptoms}

Trauma, invasive procedures, elective or cosmetic surgery affect a vast proportion of the population and around $15 \%$ of these have excessive or unaesthetic scarring. Scarring has been reported as a major source of dissatisfaction in $91 \%$ of patients who undergo a routine surgical procedure. ${ }^{13}$
Surgical injury causes a variety of wounds and symptoms depending on the type of procedure performed and the depth of cutaneous injury (Table 1). Although a scar may seem trivial in comparison to the clinical or aesthetic benefit gained, they can cause severe itching, tenderness, pain, as well as other psychosocial sequelae. (Table 2$)^{5}$

\section{Normal Wound Healing And Scar Formation}

Skin wound healing is an innate immune response to tissue injury that finishes with wound closure and restores the skin barrier function to prevent infection. It is a complex process with three, generally accepted steps, inflammation, proliferation and remodelling, which depend upon many cell types and mediators. ${ }^{11}$ It is necessary that each phase be correctly regulated to progress from one stage to another and create a neat scar. Otherwise, prolonged wound healing or excessive host responses to the injury prevent the normal process and result in unaesthetic scarring. ${ }^{11}$

The initial inflammatory response to injury is well known. ${ }^{14-16}$ However, the role the inflammation phase plays in scar development remains less well known. The initial inflammatory role is to active the adaptive immune system to prevent infection at the injury site. Macrophages (M1) clean up neutrophils, bacteria and cell debris from the wound site. ${ }^{17-19}$ Then, they change phenotype to M2 macrophages that begins the healing, proliferative/

Table I Types Of Skin Injury Caused By Medical And Aesthetic Procedures

\begin{tabular}{|l|l|}
\hline Skin Injury & Procedure \\
\hline $\begin{array}{l}\text { Widespread } \\
\text { injury }\end{array}$ & $\begin{array}{l}\text { Burn wound, electro coagulation, liquid nitrogen, } \\
\text { dermabrasion, micro-needling, Laser } \mathrm{CO}_{2}\end{array}$ \\
\hline Linear scar & $\begin{array}{l}\text { Surgical procedure, vaginal mole extraction, actinic } \\
\text { keratosis, wart removal, breast, c-section scars, } \\
\text { auricular scars }\end{array}$ \\
\hline
\end{tabular}

Table 2 Symptoms Associated With Wound Healing

Pain
Inflammation
Bruising
Itching
Erythema
Scabs
Dryness - desquamation


epithelialisation phase, producing anti-inflammatory mediators and extracellular matrices. ${ }^{17,20,21}$ If this phase is hindered, chronic wounds develop that are slow to close.

Next, the proliferative or epithelialisation phase overlaps with the inflammatory phase and usually lasts up to two to three weeks post injury. ${ }^{22}$ During this phase, wound closure continues $^{23}$ as the dermal matrix matures, and inflammatory processes continue in the reticular dermis. This makes the reticular dermis particularly sensitive to wound stress, infection, as well as patient related conditions such as age, sun exposure or genetic profile. ${ }^{24}$ Deregulation $^{25}$ in this phase is thought to cause persistent inflammation and leads to hypertrophic or in certain cases keloid scars. $^{22}$

The final, remodelling phase can last for up to a year post injury. ${ }^{26}$ During this phase, the wound contracts, collagen remodelling occurs and the new skin gains in strength. $^{22}$

\section{Factors Affecting Wound Healing}

Patient specific factors affect different parts of the healing process. Intrinsic factors include age, ethnic or genetic profile and external factors such as smoking, sun exposure, physical activity, concomitant medications, psychological stress or poor nutrition. Wound location and associated mechanophysiological conditions particularly influence the degree of scar formation and progression. Mechanical stress including skin-stretching stimulates mechanosensitive nociceptors and sensory fibers inducing neurogenic inflammation. ${ }^{27}$ Thus those wounds with greater edge tension such as the deltoid and sternal regions have a higher risk of severe scarring and keloid development. ${ }^{5}$

Severe scarring such as keloid lesions often run in families and in populations of African, Chinese and Polynesian origin. However, those of Indian and Malaysian origin and interestingly, African albinos do not seem to form keloids. People of European origin living in the tropics have a greater keloidal susceptibility. ${ }^{28}$ These scars occur spontaneously, long after the injury has healed, extend beyond the injury border and persist for long periods of time. They are firm, bosselated scars with a shiny surface and may feel tender, itchy and become hyperpigmented. ${ }^{29}$ Spontaneous keloids have been associated with certain genetic and inflammatory disorders. $^{25}$

Hypertrophic scars (HTS) occur earlier, within 4 to 8 weeks following the injury. Mostly, wound infection, trauma or excess tension prevent effective closure. Although HTS look and itch similar to keloid scars, they differ in that these scars remain within the injury edges, grow rapidly for up to 6 months and then gradually regress to a flat scar. ${ }^{29}$

It is well known that wound healing is delayed in healthy older adults ( $>65$ years) and with increasing age. $^{30}$ Increasing age is associated with morphological and structural changes as well as an altered inflammatory response. So, skin function deteriorates and each stage of the healing process is affected. ${ }^{24,31}$ Interestingly, although the maturation phase is shorter, scar quality is correct in older individuals. ${ }^{32}$ Therefore, under optimal wound care conditions, early wound healing phases may be delayed, but maturation may be hastened. However, if wound healing conditions are suboptimal, age-related immunosenescence, delays re-epithelialisation and healing.

Furthermore, concomitant medication may exacerbate wound healing delay, particularly chemotherapy, glucocorticoids and possibly long-term NSAIDS. ${ }^{24}$ Glucocorticoids inhibit wound repair by reducing the inflammatory response and chemotherapeutic drugs interfere with the immune response, cell migration and proliferation. ${ }^{33}$

Comorbid conditions such as diabetes and peripheral arterial disease ${ }^{33}$ have also been well documented to be associated with delayed healing. ${ }^{31,33}$

Smoking is also well known to hinder wound healing, and post-operative smokers have reported delayed healing, increased complications as well as reduced cosmetic outcome. $^{24}$ However, the pharmacological influence on wound healing is complex and neither nicotine or smoking can explain all the effects of smoking on wound healing. ${ }^{24}$ The current theory is that smoking impairs the initial inflammatory response and bactericidal activity. During the proliferative phase, fibroblast migration and proliferation are reduced and epithelial regeneration is hindered. ${ }^{34,35}$ Smoking cessation may improve the inflammatory cell response, but the proliferative response remains impaired. Therefore, smokers having surgery will require specific wound support during the epithelialisation phase to ensure correct wound closure.

Numerous studies have also indicated the role of psychological stress in delayed wound healing. Stress alters the immune response via the hypothalamic-pituitary-adrenal, sympathetic-adrenal medullary axes, and psychological response-induced unhealthy behaviours. ${ }^{27}$

Exposure to ultraviolet radiation has been observed to increase scar pigmentation, ${ }^{36}$ worsen clinical appearance and in some cases, cause wound hyperpigmentation. ${ }^{11,37}$ Importantly, individuals with pigmented skin are known to produce more severe scars particularly in African and 
Asian populations, and so are particularly concerned with the cosmetic appearance of visible scars. ${ }^{38}$

As intrinsic and extrinsic factors affect different phases of the healing process, combining them may further exacerbate delayed wound healing.

\section{An Optimal Microenvironment For Healing}

An ideal microenvironment for wound healing is one which is clear of debris and infection and where optimal moisture content is maintained. Moisture creates a water barrier by occluding and hydrating the stratum corneum and epidermis. ${ }^{39}$ After injury, the evaporative water loss from the wound surface can be up to four times greater than that of normal skin ${ }^{40}$ and once healed may take over a year to regain pre-wound levels. ${ }^{13}$ Spontaneous healed scars have a higher TEWL than scars from a skin graft. Similarly hypertrophic scars have a higher TEWL than normal scarring and keloid scars, which extend beyond the border of the injury have an even higher TEWL rate. ${ }^{41}$ Thus supporting cutaneous hydration is important for optimal healing.

\section{The Role Of Basic Skin Care To Optimise Healing (Table 3)}

Basic skin care may provide a barrier and maintains a moist microenvironment required for optimal healing, however there is a lack of comparative data between the various forms of post surgical care. Basic skin care seems to have a key role during the remodelling phase of wound repair and throughout maturation. Although silicone-sheets and gels ${ }^{42}$ are considered the gold standard for preventing excessive scarring with a good level of evidence, a recent comparative study showed that a hydrating cream provided equivalent occluding and hydrating properties to silicone products. This suggests that hydrating creams could be an alternative to silicones in scar prevention. ${ }^{43,44}$ Despite the limited evidence for the role of hydrating creams, the current scar management guidelines nevertheless highlight the importance of hydrating creams and silicone products to provide occlusion and hydration to support an optimal healing environment. ${ }^{11,13,44}$

Emollients and humectants, such as urea, alpha-hydroxyacid (AHA) and hyaluronic acid, ${ }^{45}$ retain moisture in the stratum corneum. This helps to maintain skin hydration to preserve skin barrier function which reduces itching and discomfort associated with scars and enhances wound healing. ${ }^{13}$ One recent systematic review about the effectiveness of moisturisers in the management of burn scars found evidence for the use of emollients, but concluded that there was insufficient evidence to inform on optimal choice. $^{12}$

Also, a rather large comparative study confirmed that rehabilitation massage effectively improved pain, pruritus, and scar characteristics in hypertrophic scars after burn injury. ${ }^{46}$

Although the evidence regarding the effect of solar UV irradiation is scarce, the current international guidelines suggest photoprotection with a maximum sun protection factor $>50$ until the scar has matured. ${ }^{13,47}$

Certain thermal spring waters have also been shown to have anti-inflammatory and immunomodulatory effects which induce accelerated skin healing and reduce itching in scar formation and dermatoses. One case study showed that balneotherapy with thermal spring water from La RochePosay in France softened the inflammatory appearance of

Table 3 Supportive Measures For Managing Scars For An Optimal Outcome

\begin{tabular}{|l|l|l|}
\hline Objective & Basic Skin Care & Role In Scar Management \\
\hline Wound Cleaning & $\begin{array}{l}\text { Thermal spring water } \\
\text { Gentle adapted cleanser } \\
\text { Disinfectant wash }\end{array}$ & $\begin{array}{l}\text { Anti-inflammatory, immunomodulatory and anti-itch } \\
\text { Reduce infection, debriding, prevent crust formation } \\
\text { Prevent infection }\end{array}$ \\
\hline Optimise Healing & $\begin{array}{l}\text { Silicone sheet } \\
\text { Silicon gels } \\
\text { Emollient with advanced hydrating properties eg, hyaluronic } \\
\text { acid with formulations adapted for massage* }\end{array}$ & $\begin{array}{l}\text { Occlusive healing, maintain skin hydration }{ }^{10} \\
\text { through to maturation. }{ }^{13} \\
\text { Soften scar tissue and prevent adhesions }{ }^{46}\end{array}$ \\
\hline $\begin{array}{l}\text { Photoprotection and } \\
\text { Camouflage }\end{array}$ & $\begin{array}{l}\text { Photoprotection SPF 50+* } \\
\text { Corrective makeup }\end{array}{ }^{4 * *}$ & $\begin{array}{l}\text { Prevent hyperpigmentation caused by UV } \text { radiation. }^{13} \\
\text { Protect healing skin and improve quality of life during } \\
\text { scar formation. }\end{array}$ \\
\hline
\end{tabular}

Notes: *These solutions can be combined in the same product. 
scars, reduced itching, facilitated elimination of crusts, and prevented formation of new crusts, thereby offering a nontraumatic method of preventing wound infection with frequent washing. ${ }^{48}$ Also, corrective cosmetic make up has been shown to improve quality of life with a significant mean DLQI score drop from $9.90 \pm 0.73$ to $3.49 \pm 0.40$ ( $\mathrm{P}>0.0001)$ for people with disfiguring dermatoses such as scars, melasma or vitiligo. ${ }^{49}$

\section{Recommendations}

This review has identified the main patient and wound factors that influence normal scar formation, and the role of basic skin care in supporting scar management, post wound closure.

General recommendations suggest that clinicians should consider optimal scar management for any patient considering or following an intervention and particularly for those whom are likely to form a hypertrophic or keloid scar. ${ }^{11,44}$ Patients at risk of delayed healing, hypertrophic or keloid scars should consider a post intervention wound care plan and scar management choices should be tailored to individual patient requirements. Patients should be encouraged to take an active role in the management of their scar. ${ }^{10}$ The type of scar management measures needs to be applied to a given wound according to the level of excessive scar risk, wound shape and location and patient's concern about the scar's appearance. Early consultation with a dermatologist may be warranted in some cases, as scars are easier to prevent than to treat. ${ }^{50}$

Optimal scar support with basic skin care should start as soon as the wound is closed and sutures are taken out. $^{11,44}$ Scars should be re-evaluated at 4-8 weeks after surgery to determine whether a hypertrophic scar is forming and medical management is required. ${ }^{13}$

Scars continue remodelling from 6-12 weeks post-surgery so occlusive therapy and sun protection should continue during this time.

\section{Acknowledgment}

The authors would acknowledge the writing support of Amanda Whereat, Medical writer, Speak the Speech Consulting, France.

\section{Disclosure}

S. Seité is employee of La Roche-Posay, France. The authors report no other conflicts of interest in this work.

\section{References}

1. Jorgensen SF, Nygaard R, Posnett J. Meeting the challenges of wound care in Danish home care. J Wound Care. 2013;22(10):540542, 544-545. doi:10.12968/jowc.2013.22.10.540

2. Young VL, Hutchison J. Insights into patient and clinician concerns about scar appearance: semiquantitative structured surveys. Plast Reconstr Surg. 2009;124(1):256-265. doi:10.1097/PRS.0b013e3181a80747

3. Vowden K, Vowden P, Posnett J. The resource costs of wound care in Bradford and Airedale primary care trust in the UK. $J$ Wound Care. 2009;18(3):93-94, 96-98, 100 passim. doi:10.12968/jowc.2009.18.3. 39814

4. Gottrup F, Henneberg E, Trangbaek R, Baekmark N, Zollner K, Sorensen J. Point prevalence of wounds and cost impact in the acute and community setting in Denmark. $J$ Wound Care. 2013;22(8):413414, 416, 418-422. doi:10.12968/jowc.2013.22.8.413

5. Bayat A, McGrouther DA, Ferguson MW. Skin scarring. BMJ. 2003;326(7380):88-92. doi:10.1136/bmj.326.7380.88

6. Onselen JV. Scars: impact and management, with a focus on topical silicone-based treatments. Br J Nurs. 2018;27(Sup12):S36-S40. doi:10. 12968/bjon.2018.27.Sup12.S36

7. Bell L, McAdams T, Morgan R, et al. Pruritus in burns: a descriptive study. J Burn Care Rehabil. 1988;9(3):305-308.

8. Bakker A, Maertens KJ, Van Son MJ, Van Loey NE. Psychological consequences of pediatric burns from a child and family perspective: a review of the empirical literature. Clin Psychol Rev. 2013;33 (3):361-371. doi:10.1016/j.cpr.2012.12.006

9. Kerwin LY, El Tal AK, Stiff MA, Fakhouri TM. Scar prevention and remodeling: a review of the medical, surgical, topical and light treatment approaches. Int J Dermatol. 2014;53(8):922-936. doi:10.1111/ijd.12436

10. Son D, Harijan A. Overview of surgical scar prevention and management. J Korean Med Sci. 2014;29(6):751-757. doi:10.3346/jkms. 2014.29.6.751

11. Sorg H, Tilkorn DJ, Hager S, Hauser J, Mirastschijski U. Skin wound healing: an update on the current knowledge and concepts. Eur Surg Res. 2017;58(1-2):81-94. doi:10.1159/000454919

12. Klotz T, Munn Z, Aromataris E, Greenwood J. The effect of moisturizers or creams on scars: a systematic review protocol. JBI Database Syst Rev Implement Rep. 2017;15(1):15-19. doi:10.11124/JBISRIR2016-002975

13. Monstrey S, Middelkoop E, Vranckx JJ, et al. Updated scar management practical guidelines: non-invasive and invasive measures. $J$ Plast Reconstr Aesthet Surg. 2014;67(8):1017-1025. doi:10.1016/j. bjps.2014.04.011

14. Strbo N, Yin N, Stojadinovic O. Innate and adaptive immune responses in wound epithelialization. Adv Wound Care. 2014;3 (7):492-501. doi:10.1089/wound.2012.0435

15. Sinno H, Prakash S. Complements and the wound healing cascade: an updated review. Plast Surg Int. 2013;2013:146764.

16. Eming SA, Martin P, Tomic-Canic M. Wound repair and regeneration: mechanisms, signaling, and translation. Sci Transl Med. 2014;6 (265):265sr266. doi:10.1126/scitranslmed.3009337

17. Sindrilaru A, Scharffetter-Kochanek K. Disclosure of the culprits: macrophages-versatile regulators of wound healing. Adv Wound Care. 2013;2(7):357-368. doi:10.1089/wound.2012.0407

18. Galli SJ, Borregaard N, Wynn TA. Phenotypic and functional plasticity of cells of innate immunity: macrophages, mast cells and neutrophils. Nat Immunol. 2011;12(11):1035-1044. doi:10.1038/ni.2109

19. Mosser DM, Edwards JP. Exploring the full spectrum of macrophage activation. Nat Rev Immunol. 2008;8(12):958-969. doi:10.1038/ nri2448

20. Fadok VA, Bratton DL, Konowal A, Freed PW, Westcott JY, Henson PM. Macrophages that have ingested apoptotic cells in vitro inhibit proinflammatory cytokine production through autocrine/paracrine mechanisms involving TGF-beta, PGE2, and PAF. J Clin Invest. 1998;101(4):890-898. doi:10.1172/JCI1112 
21. Brancato SK, Albina JE. Wound macrophages as key regulators of repair: origin, phenotype, and function. Am J Pathol. 2011;178 (1):19-25. doi:10.1016/j.ajpath.2010.08.003

22. Thiruvoth F, Mohapatra D, Sivakumar D, Chittoria R, Nandhagopal V. Current concepts in the physiology of adult wound healing. Plastic Aesthetic Res. 2015;2:5. doi:10.4103/2347-9264.158851

23. Volk SW, Bohling MW. Comparative wound healing: are the small animal veterinarian's clinical patients an improved translational model for human wound healing research? Wound Repair Regen. 2013;21:372-381. doi:10.1111/wrr.12049

24. Guo S, Dipietro LA. Factors affecting wound healing. J Dent Res. 2010;89(3):219-229. doi:10.1177/0022034509359125

25. Ogawa R. Keloid and hypertrophic scars are the result of chronic inflammation in the reticular dermis. Int $J$ Mol Sci. 2017;18:3. doi:10.3390/ijms18030606

26. Gurtner GCW, Wong VW. Healing: normal and abnormal. In: Grabb and Smith's Plastic Surgery. 6th ed. Lippincott Williams and Wilkins; 2006.

27. Ogawa R. Mechanobiology of scarring. Wound Repair Regen. 2011;19(Suppl 1):s2-s9. doi:10.1111/j.1524-475X.2011.00707.x

28. Murray JC, Pollack SV, Pinnell SR. Keloids: a review. J Am Acad Dermatol. 1981;4(4):461-470. doi:10.1016/s0190-9622(81)70048-3

29. Gauglitz GG, Korting HC, Pavicic T, Ruzicka T, Jeschke MG. Hypertrophic scarring and keloids: pathomechanisms and current and emerging treatment strategies. Mol Med. 2011;17(1-2):113125. doi:10.2119/molmed.2009.00153

30. Gosain A, DiPietro LA. Ageing and wound healing. World J Surg. 2004;28(3):321-326. doi:10.1007/s00268-003-7397-6

31. Sgonc R, Gruber J. Age-related aspects of cutaneous wound healing: a mini-review. Gerontology. 2013;59(2):159-164. doi:10.1159/000 342344

32. Bond JS, Duncan JA, Sattar A, et al. Maturation of the human scar: an observational study. Plast Reconstr Surg. 2008;121:1650-1658. doi:10.1097/PRS.0b013e31816a9f6f

33. Franz MGSD, Robson MC. Optimizing healing of the acute wound by minimizing complications. Curr Probl Surg. 2007;255(6):10691079.

34. Sorensen LT. Wound healing and infection in surgery: the pathophysiological impact of smoking, smoking cessation, and nicotine replacement therapy: a systematic review. Ann Surg. 2012;255(6):10691079. doi:10.1097/SLA.0b013e31824f632d

35. Ahn C, Mulligan P. Salcido, Richard "Sal" Smoking-the bane of wound healing: biomedical interventions and social influences. $A d v$ Skin Wound Care. 2008;21(5):227-236. doi:10.1097/01. ASW.0000305440.62402.43

36. Haedersdal M, Bech-Thomsen N, Poulsen T, Wulf HC. Ultraviolet exposure influences laser-induced wounds, scars, and hyperpigmentation: a murine study. Plast Reconstr Surg. 1998;101(5):1315-1322. doi:10.1097/00006534-199804050-00024
37. Due E, Rossen K, Sorensen LT, Kliem A, Karlsmark T, Haedersdal M. Effect of UV irradiation on cutaneous cicatrices: a randomized, controlled trial with clinical, skin reflectance, histological, immunohistochemical and biochemical evaluations. Acta Derm Venereol. 2007;87(1):27-32. doi:10.2340/00015555-0154

38. Glass DA 2nd. Current understanding of the genetic causes of keloid formation. J Investig Dermatol Symp Proc. 2017;18(2):S50-S53. doi:10.1016/j.jisp.2016.10.024

39. Mustoe TA. Evolution of silicone therapy and mechanism of action in scar management. Aesthetic Plast Surg. 2008;32(1):82-92. doi:10.1007/s00266-007-9030-9

40. Busche MN, Roettger A, Herold C, Vogt PM, Rennekampff HO. Evaporative water loss in superficial to full thickness burns. Ann Plast Surg. 2016;77(4):401-405. doi:10.1097/SAP.00000000000008 45

41. Suetake T, Sasai S, Zhen YX, Ohi T, Tagami H. Functional analyses of the stratum corneum in scars. Sequential studies after injury and comparison among keloids, hypertrophic scars, and atrophic scars. Arch Dermatol. 1996;132(12):1453-1458.

42. Marini L, Odendaal D, Smirnyi S. Importance of scar prevention and treatment-an approach from wound care principles. Dermatol Surg. 2017;43(Suppl 1):S85-S90.

43. Hoeksema H, De Vos M, Verbelen J, Pirayesh A, Monstrey S. Scar management by means of occlusion and hydration: a comparative study of silicones versus a hydrating gel-cream. Burns. 2013;39 (7):1437-1448. doi:10.1016/j.burns.2013.03.025

44. Mustoe TA, Cooter RD, Gold $\mathrm{MH}$, et al. International clinical recommendations on scar management. Plast Reconstr Surg. 2002;110(2):560-571. doi:10.1097/00006534-200208000-00031

45. Loden M. The clinical benefit of moisturizers. J Eur Acad Dermatol Venereol. 2005;19(6):672-688; quiz 686-677. doi:10.1111/j.14683083.2005.01326.x

46. Cho YS, Jeon JH, Hong A, et al. The effect of burn rehabilitation massage therapy on hypertrophic scar after burn: a randomized controlled trial. Burns. 2014;40(8):1513-1520. doi:10.1016/j.burns.2014. 02.005

47. MH BB G, Clementoni MT, Gauglitz GG, Nahai F, Murcia C. Updated international clinical recommendations on scar management: part 1-evaluating the evidence. Dermatol Surg. 2014;40(8):817-824. doi: $10.1111 /$ dsu.0000000000000049

48. Seite S. Thermal waters as cosmeceuticals: La Roche-Posay thermal spring water example. Clin Cosmet Investig Dermatol. 2013;6:1-6.

49. Seite S, Deshayes P, Dreno B, et al. Interest of corrective makeup in the management of patients in dermatology. Clin Cosmet Investig Dermatol. 2012;5:123-128. doi:10.2147/CCID.S33172

50. Meaume S, Le Pillouer-Prost A, Richert B, Roseeuw D, Vadoud J. Management of scars: updated practical guidelines and use of silicones. Eur J Dermatol. 2014;24(4):435-443. doi:10.1684/ejd.2014. 2356
Clinical, Cosmetic and Investigational Dermatology is an international, peer-reviewed, open access, online journal that focuses on the latest clinical and experimental research in all aspects of skin disease and cosmetic interventions. This journal is indexed on CAS.
The manuscript management system is completely online and includes a very quick and fair peer-review system, which is all easy to use. Visit http://www.dovepress.com/testimonials.php to read real quotes from published authors. 